\title{
Influence of $\mathrm{V}$ and Heat Treatment on Characteristics of WMoNbTaV Refractory High-Entropy Alloy Coatings by Mechanical Alloying
}

\author{
Chun-Liang Chen ${ }^{1, *}$ and Sutrisna ${ }^{1,2}$ \\ 1 Department of Materials Science \& Engineering, National Dong Hwa University, Shou-Feng, \\ Hualien 97401, Taiwan; 810422003@gms.ndhu.edu.tw \\ 2 Department of Mechanical Engineering, Institut Teknologi Nasional, Yogyakarta 55281, Indonesia \\ * Correspondence: chunliang@gms.ndhu.edu.tw; Tel.: +886-3-890-3205
}

Citation: Chen, C.-L.; Sutrisna.

Influence of $\mathrm{V}$ and Heat Treatment on Characteristics of WMoNbTaV Refractory High-Entropy Alloy Coatings by Mechanical Alloying. Coatings 2021, 11, 265. https:// doi.org/10.3390/coatings11030265

Academic Editor: Petrică Vizureanu

Received: 26 January 2021

Accepted: 18 February 2021

Published: 24 February 2021

Publisher's Note: MDPI stays neutral with regard to jurisdictional claims in published maps and institutional affiliations.

Copyright: (c) 2021 by the authors. Licensee MDPI, Basel, Switzerland. This article is an open access article distributed under the terms and conditions of the Creative Commons Attribution (CC BY) license (https:// creativecommons.org/licenses/by/ $4.0 /)$.

\begin{abstract}
Refractory high-entropy alloy (RHEA) is one of the most promising materials for use in high-temperature structural materials. In this study, the WMoNbTaV coatings on 304 stainless steel substrates has been prepared by mechanical alloying (MA). Effects of V addition and subsequent heat treatment on properties of the $\mathrm{WMoNbTaV}$ coatings were investigated. The results show that the RHEA coatings with nanocrystalline body-centered cubic (BCC) solid-solution phase were generated by the mechanical alloying process. The presence of the $\mathrm{V}$ element promotes a uniform microstructure and homogeneous distribution of composition in the RHEA coatings due to improving alloying efficiency, resulting in an increase of hardness. After the annealing treatment of the RHEA coatings, microstructure homogeneity was further enhanced; however, the high affinity of Ta for oxygen causes the formation of Ta-rich oxides. Annealing also removes strain hardening generated by high-energy ball milling and thus decreases the hardness of the RHEA coating and alters microstructure evolution and mechanical properties.
\end{abstract}

Keywords: refractory high-entropy alloy; coating; mechanical alloying; heat treatment

\section{Introduction}

High-entropy alloy (HEA) contains multiple principal elements, often five or more in equimolar or near-equimolar ratios [1-3], and tends to form a disordered solid solution in a simple crystal of BCC, face-centered cubic (FCC), and hexagonal close-packed (HCP) without intermetallic compound formation [4-6]. The different constituents of the HEAs have been extensively studied due to their high strength, good thermal stability, and resistance to wear, fatigue, oxidation, and corrosion [7-11].

In the past few years, refractory high-entropy alloys composed of refractory elements with high melting points have attracted increasing attention because of their superior radiation resistance, high thermal stability, and excellent retention of strength at elevated temperatures [11-13]. Therefore, refractory HEAs have great potential applications in the nuclear power generation, aerospace, and automobile industries [14-16].

Recently, HEA coating has been considered as an option for the surface protection of materials. A number of researches [17-20] have shown that better wear and corrosion resistance and excellent mechanical and electrical properties were obtained by using HEA coatings. HEA coatings can be produced by the different advanced techniques including magnetron sputtering, laser cladding, spraying, electrodeposition, and plasma-transferred arc cladding [21-25]. In recent years, mechanical alloying is one of the most promising techniques for producing HEA coatings by solid-state powder processing. For instance, $\mathrm{Li}$ et al. illustrate that $\mathrm{Cr}$ coating prepared by mechanical alloying was well bonded with $\mathrm{Cu}$ substrate [26]. Several studies have shown the development and characteristics of HEA coatings by mechanical alloying [27-29]. Ge et al. reported that the CuZrAlTiNi 
HEA coating by mechanical alloying has high microhardness, uniformly dispersed nanosized precipitates, phase boundary strengthening, and solid-solution strengthening [27]. Additionally, Shang et al. demonstrated that $\mathrm{CoCrFeNi}$ and $\mathrm{CoCrFeNiCu}$ HEA coatings by mechanical alloying with vacuum hot-pressing sintering (VHPS) technique exhibit excellent mechanical and magnetic properties [28]. Kang et al. also proposed that the $\mathrm{WNbMoTaV}$ HEA fabricated via the powder metallurgical process showed the best compressive yield strength and high densification in comparison with the processing by arc-melting and casting [29]. However, the research of HEA coatings based on refectory elements fabricated by mechanical alloying is still very limited.

Therefore, in the present work, the two RHEA coatings (WNbMoTa and WNbMoTaV) on the substrate of stainless steels produced by mechanical alloying were investigated. The annealing treatment of the refractory HEA coatings was also introduced in this work. This study aims to clarify the effects of $\mathrm{V}$ addition and annealing treatment on the synthesis and characteristics of the refractory $\mathrm{WNbMoTaV}$ HEA coatings. The influence of mechanical alloying on the properties of coatings would also be discussed in this paper.

\section{Materials and Methods}

The raw materials used in this study were $\mathrm{W}, \mathrm{Mo}, \mathrm{Nb}, \mathrm{Ta}$, and $\mathrm{V}$ elemental powders with a purity of $99.9 \%$ and particle size from $20-50 \mu \mathrm{m}$. An AISI 304 austenitic stainless steel was used as a substrate (a disk size of diameter $=6 \mathrm{~mm}$ and thickness $=2 \mathrm{~mm}$ ). The surface of the substrate was prepared by conventional grinding/polishing procedures. The elemental powders were loaded into a vial, together with the stainless-steel substrate. A vial loaded with powders and substrates was sealed in a glove box with a highly purified argon atmosphere. In the present work, the WNbMoTa and WNbMoTaV HEAs were coated on substrates of austenitic stainless steels by mechanical alloying. An annealing treatment was further performed on the WNbMoTaV HEA coating sample under a high vacuum furnace $\left(10^{-5}\right.$ torr $)$ at $950^{\circ} \mathrm{C}$ for $2 \mathrm{~h}$. The three model coatings with refractory HEAs were named as "WNbMoTa", "WNbMoTaV", and "WNbMoTaV-A" in this study. The nominal compositions of each model RHEA coating can be seen in Table 1. Mechanical alloying was conducted with the PM100 planetary ball mill (Retsch GmbH, Haan, Germany) at $300 \mathrm{rpm}$ under an argon atmosphere for different durations: 4, 8, 16, and $24 \mathrm{~h}$. The vial and ball materials used in the study were tungsten carbide with the ball to powder ratio of 10:1. The model RHEA powders and coatings were characterized by X'Pert PRO X-ray diffractometer (XRD) (PANalytical, Almelo, The Netherlands). The crystallite size and lattice strain were calculated using Scherrer's formula [30]. Microstructure characterization and chemical composition analysis of the model RHEA coatings were examined using a Hitachi-4700 scanning electron microscope (SEM) (Hitachi High-Tech Corporation, Tokyo, Japan) with energy-dispersive X-ray spectroscopy (EDS) at an accelerating voltage of $15 \mathrm{keV}$. The hardness testing was performed on Future Tech FM-310 Micro Vickers Hardness Tester machine (Future-Tech Corporation, Kawasaki, Japan) using a square-based diamond pyramid indenter with a load of $25 \mathrm{~g}$ for $15 \mathrm{~s}$.

Table 1. The nominal compositions of the model refractory high-entropy alloy (RHEA) coatings (at.\%).

\begin{tabular}{ccccccc}
\hline RHEA Coating & W & Mo & Nb & Ta & V & Annealing \\
\hline WMoNbTa & 30 & 30 & 20 & 20 & - & - \\
\hline WMoNbTaV & 20 & 20 & 20 & 20 & 20 & - \\
\hline WMoNbTaV-A & 20 & 20 & 20 & 20 & 20 & $950{ }^{\circ} \mathrm{C}$ for $2 \mathrm{~h}$ \\
\hline
\end{tabular}

\section{Results and Discussion}

\subsection{Characterization of the Model RHEA Powders}

Figure 1a shows the XRD spectra of the WMoNbTa HEA milled powders as a function of milling time. The strong diffraction peaks of the un-milled powders correspond to the 
starting elements ( $\mathrm{W}, \mathrm{Mo}, \mathrm{Nb}$, and $\mathrm{Ta})$. The elements of $(\mathrm{W}, \mathrm{Mo})$ and $(\mathrm{Ta}, \mathrm{Nb})$ have a similar crystal structure, and thus their peaks tend to overlap each other. After $4 \mathrm{~h}$ of milling, the peaks of $(\mathrm{Ta}, \mathrm{Nb})$ at $2 \theta$ of $\sim 82^{\circ}$ and $\sim 95^{\circ}$ disappeared, suggesting the formation of a partial solid solution. In addition, the peaks of $\mathrm{W}$ and Ta elements are dominant in the early stage of milling $(4 \mathrm{~h})$; however, Mo and $\mathrm{Nb}$ elements have greatly declined, which could be associated with their low melting points compared to the $\mathrm{W}$ and Ta elements, respectively. It has been reported that the alloying rate correlates well with the melting point during ball milling [31]; therefore, in this case, the low melting point of $\mathrm{Mo}$ and $\mathrm{Nb}$ elements would have a higher alloying rate and accelerate solid-state diffusion rate in the unlimited solid solubility of the ( $\mathrm{W}-\mathrm{Mo})$ and $(\mathrm{Ta}-\mathrm{Nb})$ isomorphous systems during ball milling. As the milling times increased to $8 \mathrm{~h}$ and $16 \mathrm{~h}$, the Ta peaks at $2 \theta$ of $\sim 55^{\circ}$ and $\sim 70^{\circ}$ disappeared. A number of diffraction peaks are margining and tend to form a single BCC solid-solution phase located at $2 \theta$ of $40^{\circ}, 58^{\circ}, 73^{\circ}, 87^{\circ}$ and $102^{\circ}$. Moreover, in this stage, the diffraction peak at the low $2 \theta$ angle $\left(\sim 38^{\circ}\right)$ still remains the transient phase corresponding to the Ta-rich phase. It has been proposed that the transient phases of TaW, TaMo, and MoNb can be found in NbMoTaW HEA powders after $12 \mathrm{~h}$ of milling, indicating that a metastable solid solution between elements can be produced during the alloying process [32]. At the final stage of milling $(24 \mathrm{~h})$, it was demonstrated that the five diffraction peaks of the BCC solid-solution phase were clearly observed in WMoNbTa HEA powders. The result indicates that all of the elements were dissolved into the $\mathrm{WMoNbTa}$ HEA system and confirmed that a single-phase with BCC crystal structure is successfully synthesized by mechanical alloying. The analysis also revealed that peak broadening and peak shifting were apparently observed with increasing milling time in the XRD diffraction patterns. It is generally associated with grain size reduction, an increase of internal strain, and the formation of solid solution [33].

Figure $1 \mathrm{~b}$ shows the XRD spectra of the $\mathrm{WMoNbTaV}$ HEA milled powders as a function of milling time. The XRD result has a similar tendency to that of the WMoNbTa HEA powders, see Figure 1a. At the un-milled powders, the peaks of the V element were detected, and the intensity of the peaks is relatively lower than other elements due to its low atomic mass. After $8 \mathrm{~h}$ of milling, the diffraction peaks of $\mathrm{V}$ and Ta disappeared; however, the peaks of $\mathrm{W}$ and Mo elements approached each other and finally merged together. This indicates that all elements had dissolved into the RHEA system and formed a single BCC solid-solution phase. It should be noted that there are still remaining transient phases (TaW or TaMo) located at $2 \theta$ of $38^{\circ}$ in the XRD pattern after $16 \mathrm{~h}$ of milling. The presence of the transient phase (Ta-rich) is the same in the case of the WMoNbTa powders milled for $16 \mathrm{~h}$, see Figure $1 \mathrm{a}$. As the milling time increased to $24 \mathrm{~h}$, the complete disappearance of all the elements peaks and the formation of a single-phase into the BCC solid solution were obtained. The analysis also revealed that peak broadening and peak shifting were apparently observed with increasing milling time in the XRD diffraction patterns. The result suggests that severe lattice distortion and the change of crystallite size were induced by crystal defects during ball milling, which is generally associated with grain size reduction, an increase of internal strain, and the formation of solid solution [33].

Figure 2 shows the variation of the crystallite size and lattice strain of the $\mathrm{WMoNbTaV}$ HEA powders as a function of milling time. In the initial stage of milling $(4 \mathrm{~h})$, it can be clearly seen that a significant reduction of crystallite size and increase of lattice strain were obtained. It is believed that severe plastic deformation induced by ball collisions provides large strain energy in the milled powders, which promotes the formation of transient phases in the early stage of milling. With increasing milling time, a continued increase in the lattice strain and reduction of crystallite size were observed. It suggests that the repeated fracture and cold welding during the milling process encouraged the formation of RHEAs with the dominant BCC solid-solution phase. 
(a)
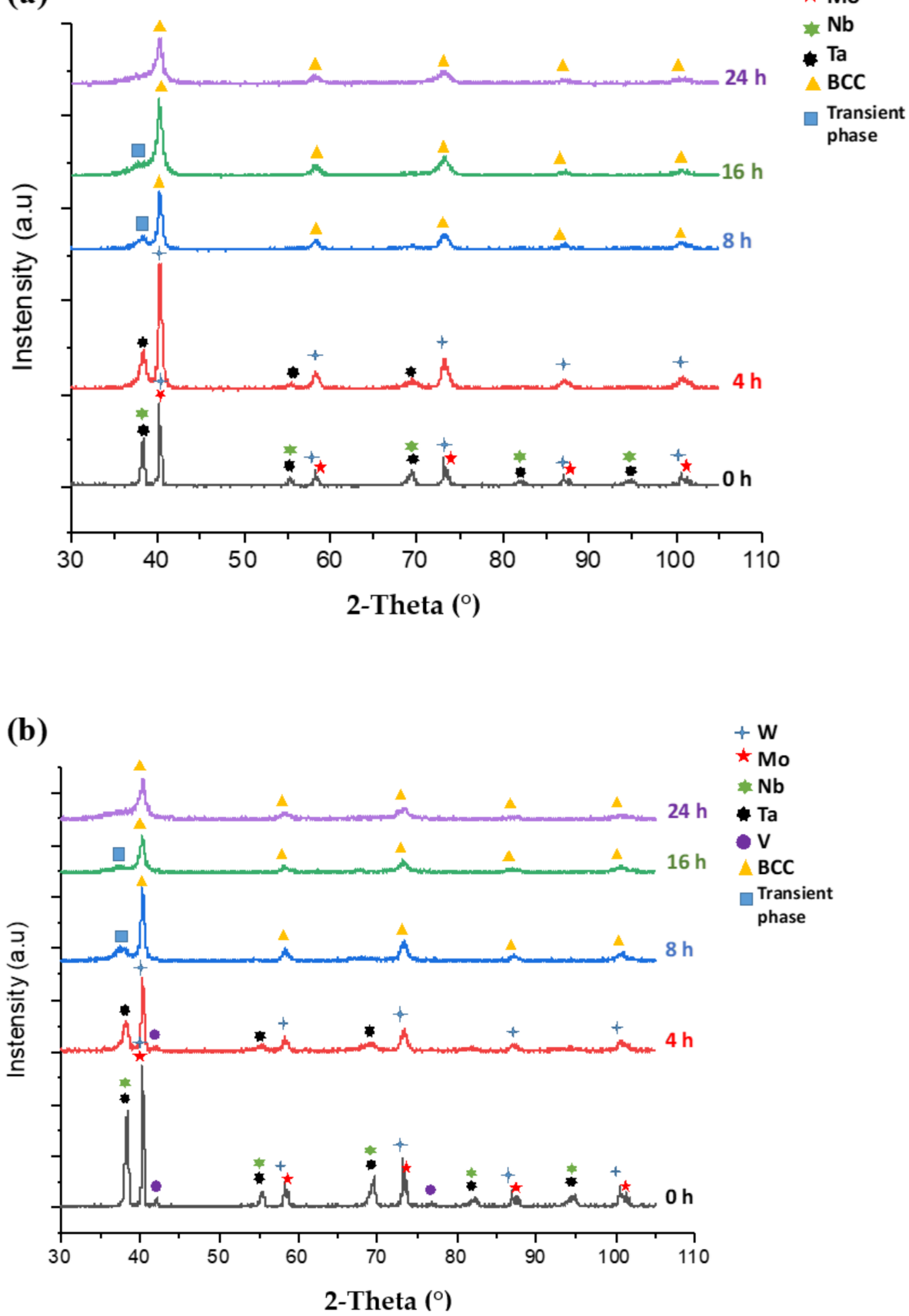

Figure 1. X-ray diffractometer (XRD) spectra of (a) the WMoNbTa and (b) WMoNbTaV high-entropy alloy (HEA) powders for different milling durations: 0, 4, 8, 16 and $24 \mathrm{~h}$.

\subsection{Characterization of Model RHEA Coatings}

\subsubsection{SEM Observation/EDS Analysis}

Figure 3 shows the cross-sectional SEM images of the WMoNbTaV HEA deposited on the substrate of stainless steel at different milling times. Three regions were observed in the microstructure including the incomplete milling powder, coating layer, and substrate. In the initial stage of milling ( 4 and $8 \mathrm{~h}$ ), the non-uniform microstructure with segregation of elements and an irregular interface between the coating and substrate were found, see Figure 3a,b. Furthermore, there are a few microcracks and microvoids formed on the coating layer. In this stage, the incomplete mechanical alloying leads to a significant effect on the low densification and microstructure inhomogeneity of the RHEA coatings, which caused deterioration of the mechanical properties. After long milling durations 
(16 and $24 \mathrm{~h}$ ), it promotes more homogeneous microstructure distribution and improved densification of the RHEA coatings (see Figure 3c,d). In this case, at the final stage of milling, the formation of BCC solid-solution phase with a uniform distribution of elements in the coating can be finally achieved. Besides, it is obvious to see an increasing trend in coating thickness with an increase in milling time (from $\sim 30 \mu \mathrm{m}$ for $4 \mathrm{~h}$ of milling to $\sim 60 \mu \mathrm{m}$ for $24 \mathrm{~h}$ of milling).

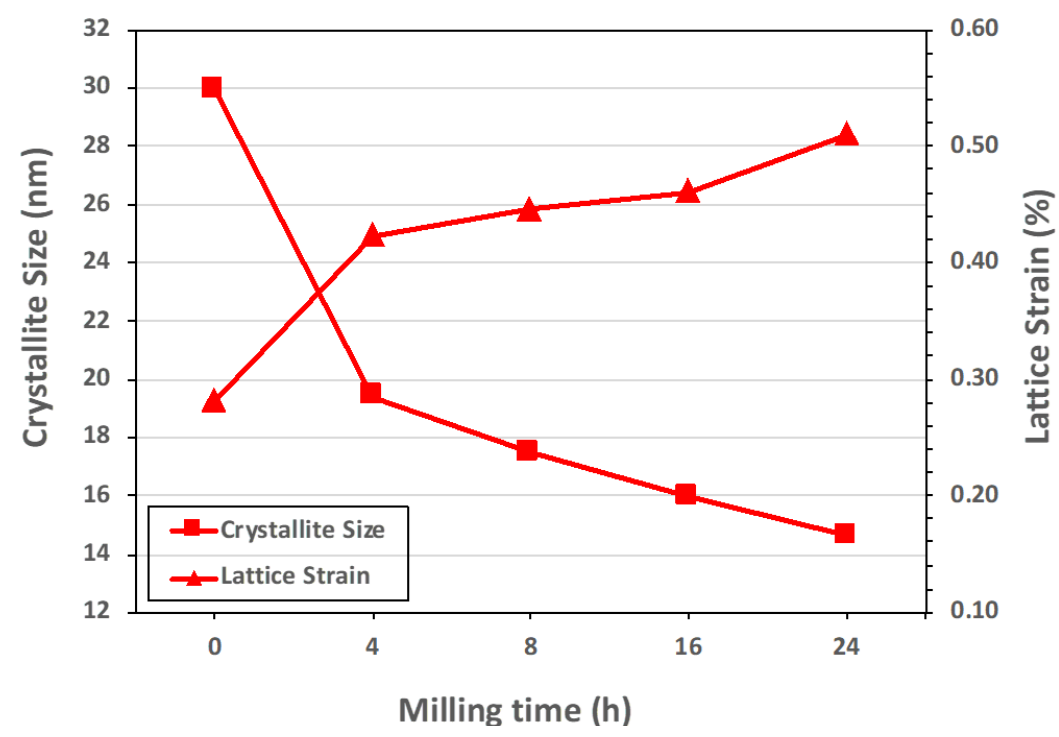

Figure 2. Variation of crystallite size and lattice strain of the WMoNbTaV HEA powders at different milling times.
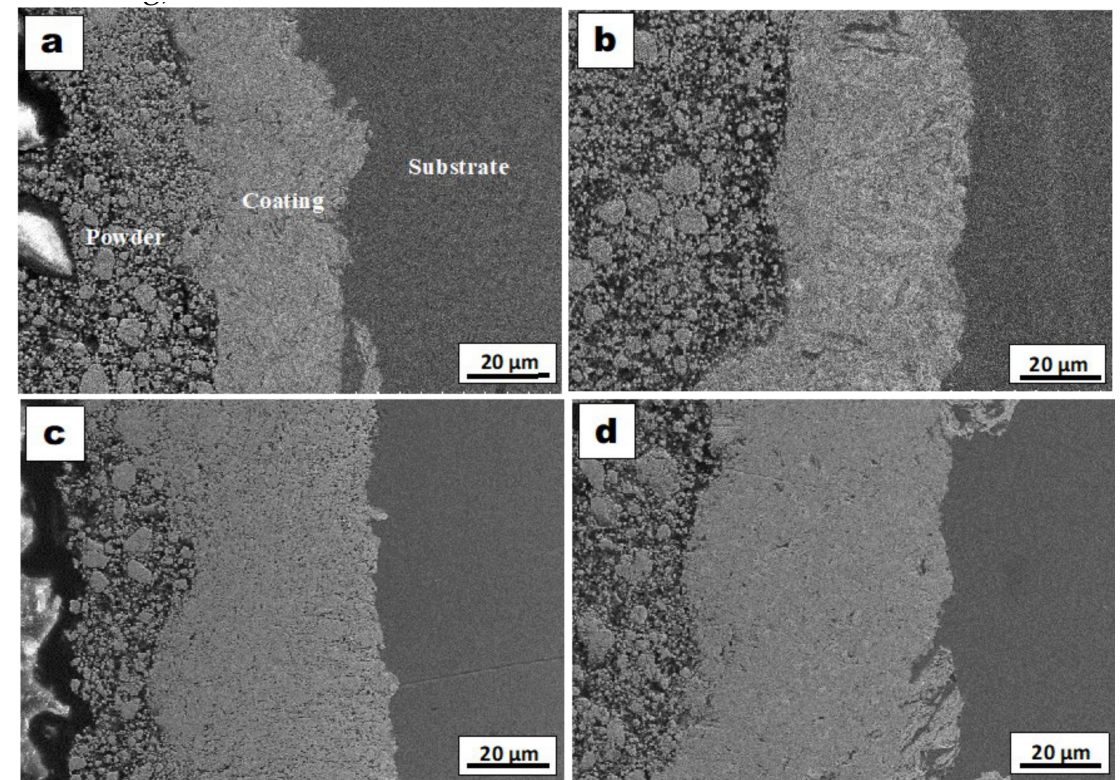

Figure 3. Cross-sectional SEM images of the WMoNbTaV HEA coating on the stainless-steel substrate for (a) 4, (b) 8, (c) 16, and (d) 24 h of milling.

Figure 4 also shows the EDS mapping of the WMoNbTaV HEA coating milled for $24 \mathrm{~h}$. All of the alloying elements are observed on the EDS maps and homogenously distributed on the coating layer. It confirmed that a uniform distribution of elements in the materials can be obtained and correlated to a single BCC solid-solution phase formed by mechanical alloying. 


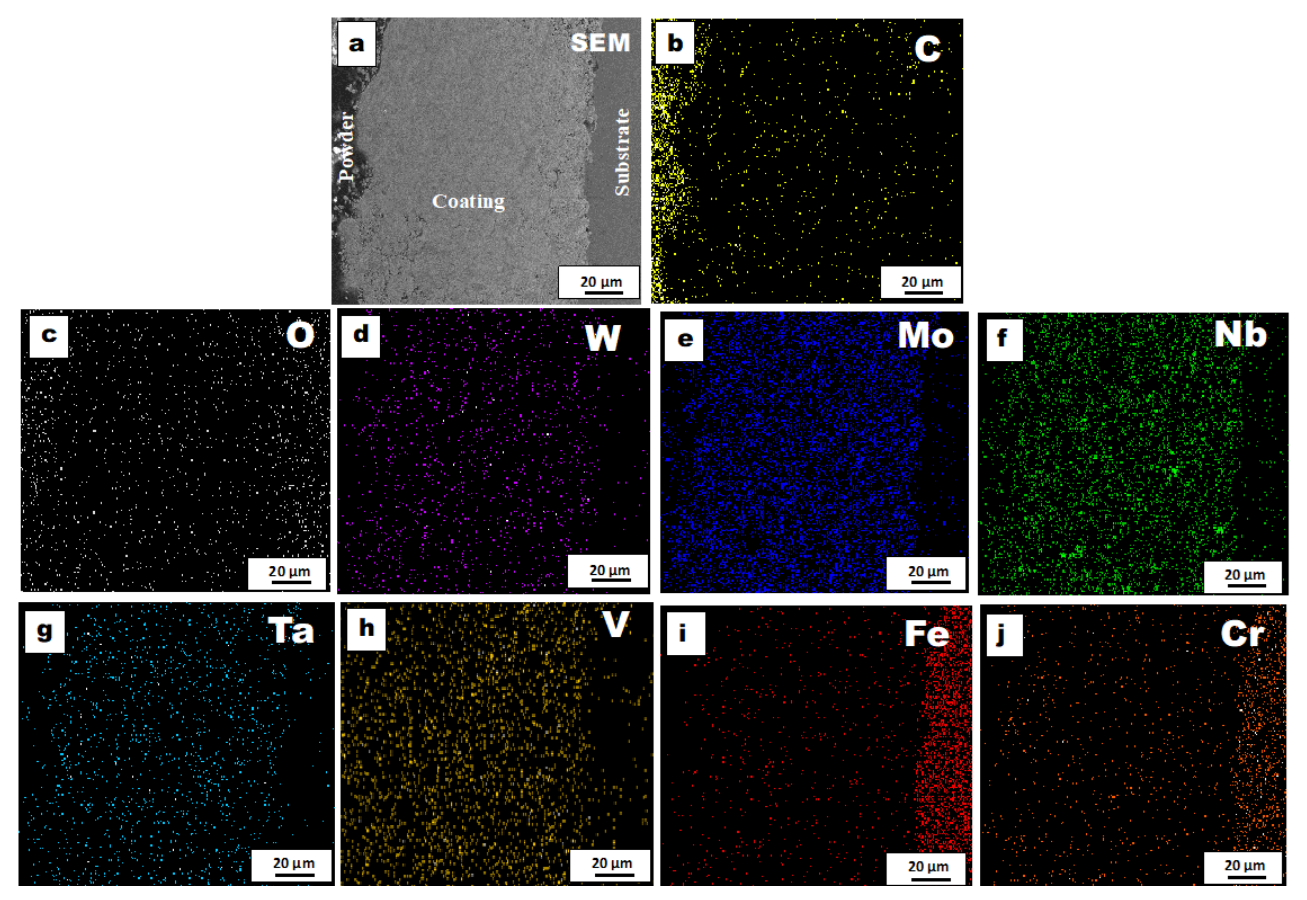

Figure 4. The energy-dispersive X-ray spectroscopy (EDS) mapping of the WMoNbTaV HEA coating milled for $24 \mathrm{~h}$ (a) SEM image, (b) C map, (c) O map, (d) W map, (e) Mo map, (f) Nb map, (g) Ta map, (h) V, (i) Fe map, and (j) Cr map.

Figure 5 displays the cross-sectional SEM images and EDS analysis of the three model HEA coatings milled for $24 \mathrm{~h}$. The microstructure of the WMoNbTa HEA coating can be seen in Figure 5 a and demonstrates a non-uniform distribution of microstructure with a number of microcracks and pores. EDS analysis revealed that a homogenous distribution of elements was found in the middle area of the coating, see point A. The EDS analysis at the interface, see point $B$, is more than $1 \mu \mathrm{m}$ distance from the substrate, which has less influence on picking up X-rays from the substrate. The distribution of elements at the interface indicates a high concentration of Fe and $\mathrm{Cr}$ elements. In this case, it is most likely that the very hard coating powders with refractory metal elements can wear the soft stainless-steel substrate due to severe deformation and stain energy induced by highenergy ball milling, which dominated all the interaction and diffusion processes between the coating and substrate. Figure $5 b$ shows the cross-sectional microstructure of the WMoNbTaV HEA coating. It reveals that the homogeneous microstructure was developed. EDS analysis also indicates a consistent distribution of elements in the coating region, see point $\mathrm{C}$, which has a close composition with the designed WMoNbTaV model HEA in an equal concentration of 20 at. \% for each element. The results confirmed that a complete solid solution of the WMoNbTaV HEA coating can be obtained by mechanical alloying. It also implied that the presence of $\mathrm{V}$ elements plays an important role in determining microstructure evolution and homogeneity of the materials. It has been reported that the addition of $\mathrm{V}$ in the $\mathrm{WMoNbTaV} \mathrm{HEA}$ system can refine the microstructure and obtains a uniform distribution of grain size [16]. WNbMoTaV HEA fabricated using mechanical alloying also provides increased densification (99.5\%) and compressive yield strength, which were much higher than that of RHEAs produced by arc-melting and casting [29]. 

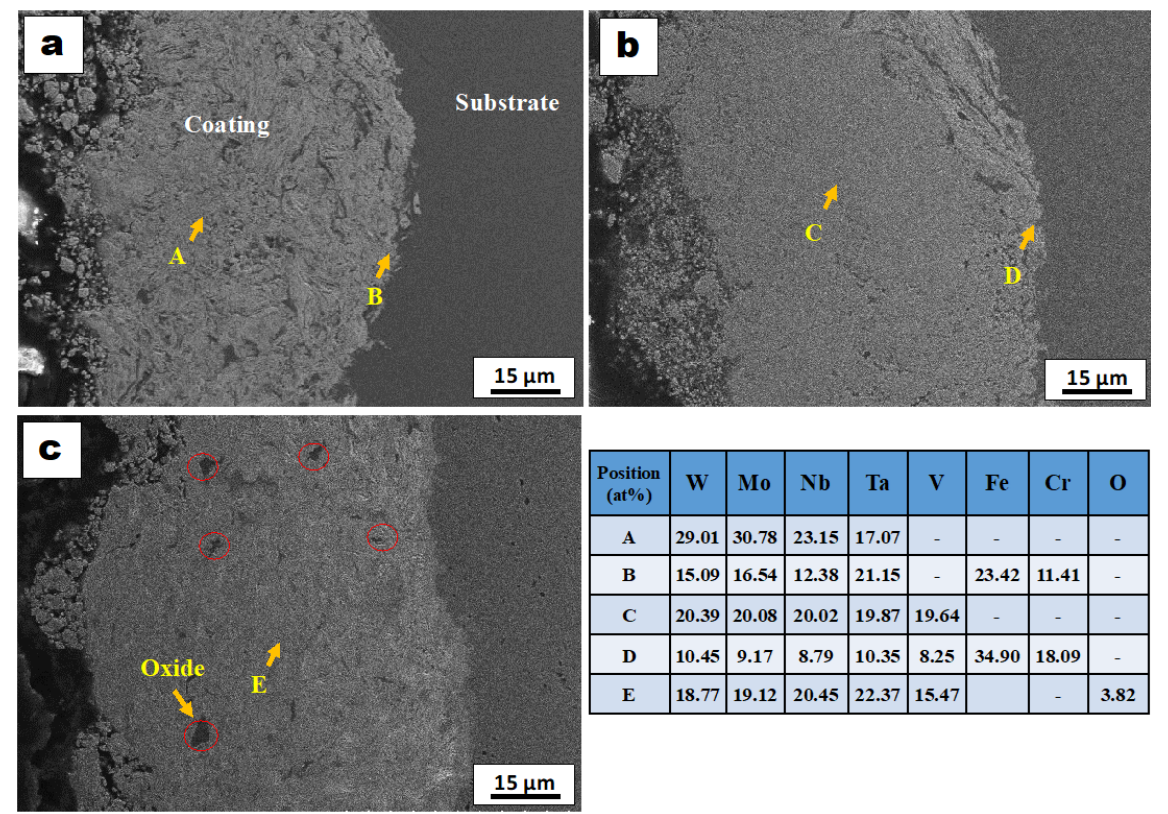

Figure 5. Cross-sectional SEM images and EDS analysis of (a) the WMoNbTa, (b) WMoNbTaV, and (c) WMoNbTaV-A coatings.

On the other hand, Figure $5 \mathrm{c}$ shows the cross-sectional microstructure of the $\mathrm{WMoNbTaV}$ model HEA coating after annealing treatment at $950{ }^{\circ} \mathrm{C}$. A uniform microstructure and distribution of alloying elements were also received in this coating sample, see point $\mathrm{E}$; however, a number of oxides appeared as dark particles were found in the coating region. (see red circles in Figure 5c). It suggests that high-temperature annealing promotes a rapid reaction of the alloying elements and residual oxygen gas located on the pores of the coating, leading to the formation of numerous oxides on the materials.

Figure 6 illustrates the cross-sectional morphology and EDS line profile spectra of the elemental distribution in the $\mathrm{WMoNbTa}, \mathrm{WMoNbTaV}$, and $\mathrm{WMoNbTaV}-\mathrm{A}$ model HEA coatings. A high concentration of $\mathrm{Fe}$ and $\mathrm{Cr}$ was found in all the model RHEA coatings corresponds to the stainless-steel substrate. A large variation of element distribution can be seen in the WMoNbTa coating sample, see Figure 6a. It might contribute to the presence of heterogeneous microstructure, porosity, and microcracks on the coating layer. In contrast, a uniform distribution of alloying elements was achieved in the WMoNbTaV HEA coating, see Figure $6 \mathrm{~b}$, which can be related to the enhanced homogeneity of microstructure. It is reasonable to assume that the addition of $\mathrm{V}$ in the brittle RHEA coatings can provide the ductility of the alloy system and therefore achieves a balance between cold welding and fracturing during ball milling. Consequently, it facilitates the alloying process and accelerates the formation of the solid-solution phase, as well as increases the diffusion rate and solid solubility of the RHEA system. Figure $6 \mathrm{c}$ demonstrates that more inhomogeneous distribution of elements was obtained in the $\mathrm{WMoNbTaV}$ HEA coating after annealing. It implied that the annealing treatment promotes the formation of oxide particles, which alters the constitution of the RHEA system, resulting in the change of the elemental distribution, microstructure homogeneity, and densification of the RHEA coating. A small amount of oxygen was also been detected in the EDS line scan of the WMoNbTaV-A HEA coating, see Figure 6c, which can be correlated to the formation of oxides after high-temperature annealing. 


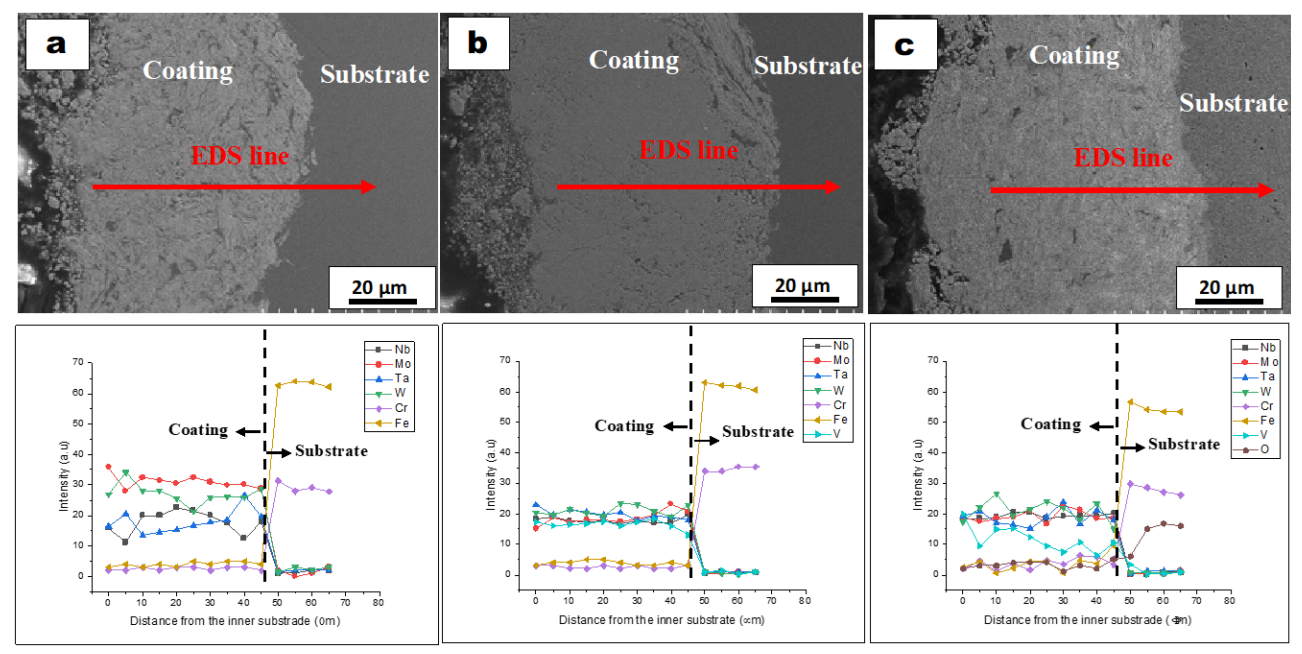

Figure 6. Cross-sectional morphologies and EDS line profile spectra of the elemental distribution of (a) the WMoNbTa, (b) WMoNbTaV, and (c) WMoNbTaV-A coatings.

An enlarged SEM image of the WMoNbTaV HEA coating after annealing can be seen in Figure 7. A large number of oxides that appeared as a dark region were found and have been identified as Ta-rich oxides by EDS analysis. In addition, the chemical composition determined by EDS mapping demonstrates that the high levels of oxygen (26.61 at.\%) and carbon (24.29 at.\%) contents were obtained, see the table of Figure 7 . In this case, oxides and carbides are therefore expected to form on the RHEA coating during annealing treatment. Apart from sintering or annealing effects, it has been proposed that the mechanical alloying has extensive contamination of carbon and oxygen to the materials more than $1 \mathrm{wt} . \%$ even just after $10 \mathrm{~h}$ of milling $[34,35]$. Such contamination can be more prevalent in refractory HEAs due to their higher hardness. It should be noted that the addition of a processing control agent and the use of grinding media during mechanical alloying are responsible for carbon and oxygen contamination [35].

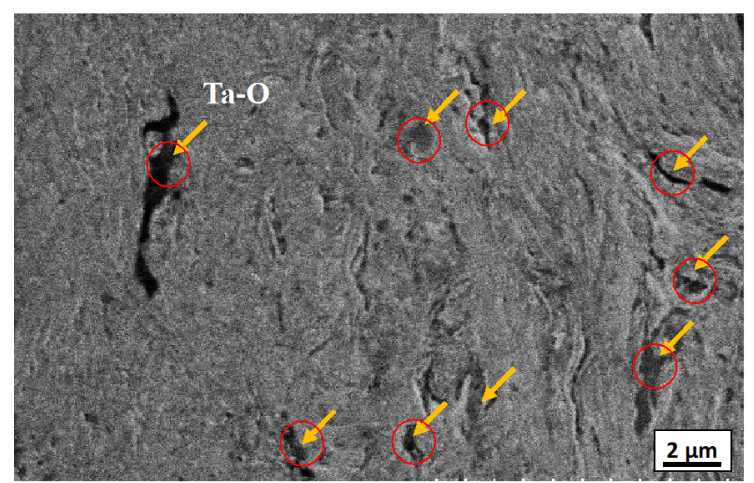

\begin{tabular}{|c|c|c|}
\hline Element & Weight\% & Atomic\% \\
\hline $\mathbf{C}$ & 8.79 & 24.29 \\
\hline $\mathbf{O}$ & 12.56 & 26.61 \\
\hline $\mathbf{V}$ & 8.06 & 9.42 \\
\hline $\mathbf{N b}$ & 12.69 & 9.17 \\
\hline $\mathbf{M o}$ & 12.92 & 8.60 \\
\hline $\mathbf{T a}$ & 20.36 & 8.70 \\
\hline $\mathbf{W}$ & 24.29 & 8.69 \\
\hline
\end{tabular}

Figure 7. SEM image of the enlarged WMoNbTaV-A coating milled for $24 \mathrm{~h}$.

\subsubsection{XRD Analysis}

Figure 8a shows the XRD spectra of the WMoNbTaV HEA coating at the different milling durations. It is obvious that at the beginning of milling $(4 \mathrm{~h})$, all constituent elements were identified by the strong diffraction peaks due to the incomplete milling process. However, with increasing milling time, peak broadening and shifting were observed. Some of the peaks disappeared or merged. It indicates the introduction of crystal defects, high lattice strain, and formation of solid solution. Finally, a single BCC solid-solution phase was obtained after a long milling duration. The XRD result of the WMoNbTaV HEA coating is very similar to that of the $\mathrm{WMoNbTaV}$ powders (see Figure $1 \mathrm{~b}$ ). However, it was clearly revealed that there is still one peak visible at $2 \theta$ of $38^{\circ}$ in the coating sample milled for $24 \mathrm{~h}$. It can be assumed that a small amount of the transient phase (Ta-rich phase) can remain in 
the RHEA coating at the final stage of milling. It is believed that the Ta element has a high melting point in the RHEA system, and thereby, the alloying rate could be reduced and could slow down the solid-state diffusion rate during ball milling [33]. It is expected that a further milling process (more than $24 \mathrm{~h}$ of milling) could transfer the transient phase into a solid-solution phase of the BCC structure. Furthermore, it might be also related to the impact energy input in the milled powders, which is larger than that of the coating layer during mechanical alloying process [32]. In this case, the formation of transient phases would not be observed in the powder form under a long milling duration $(24 \mathrm{~h})$, see XRD pattern of the $\mathrm{WMoNbTaV}$ powders milled for $24 \mathrm{~h}$ in Figure $1 \mathrm{~b}$.
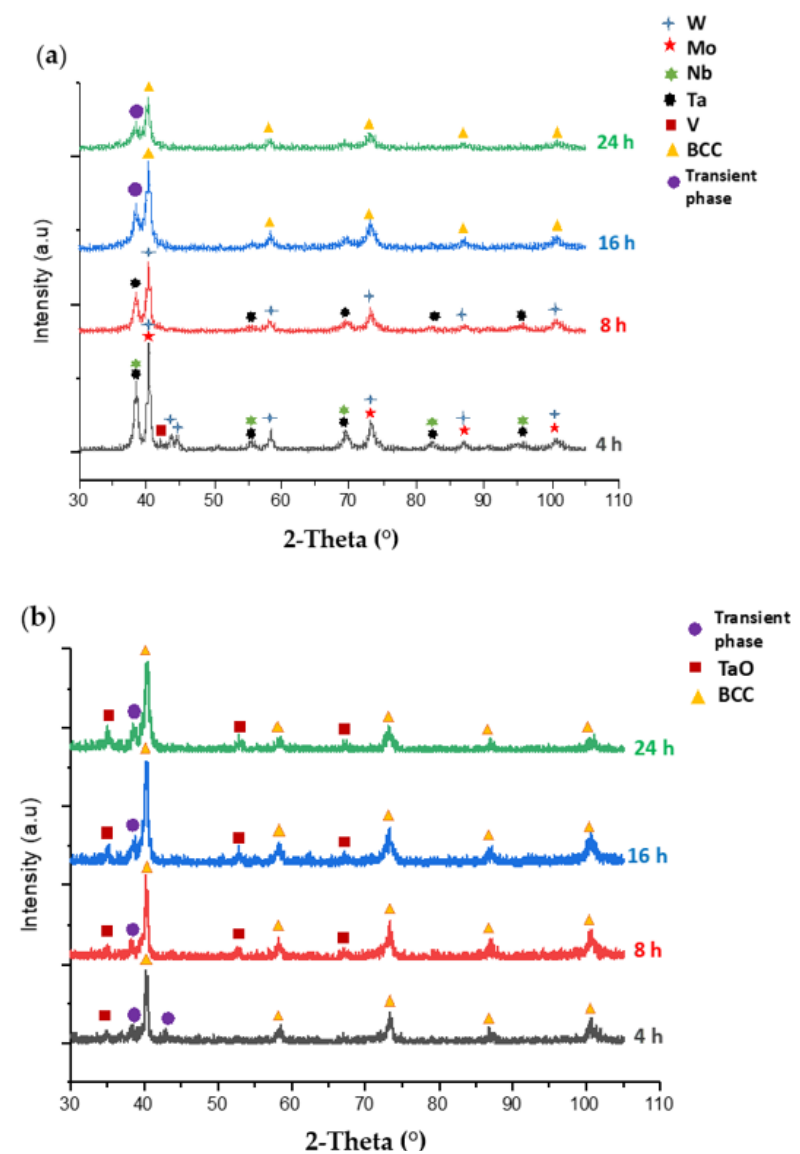

Figure 8. XRD spectra of (a) the $\mathrm{WMoNbTaV}$ and (b) WMoNbTaV-A HEA coatings for different milling durations: $4,8,16$, and $24 \mathrm{~h}$.

On the other hand, the XRD patterns of the WMoNbTaV-A HEA coating for different milling times can be seen in Figure 8b. The main peaks corresponding to BCC solidsolution phase were found at all milling times. It implied that the annealing treatment increases the rate of diffusion by providing the thermal energy needed for solid solution and thereby accelerates the formation of BCC solid-solution phase at the initial stage of milling. However, the high temperature of annealing can also result in oxidation of the RHEA coatings. It can be seen clearly that a few diffraction peaks corresponding to $\mathrm{TaO}$ have been identified in all milling times. The XRD investigations are in good agreement with the results obtained from the SEM/EDS, see Figure 7, which shows the formation of oxide particles in the coating layer. Furthermore, there is no peak broadening effect on the spectra of the coatings with increasing milling time after annealing at $950{ }^{\circ} \mathrm{C}$. It suggests that sufficient thermal energy provided by the annealing treatment facilities the diffusion of atoms between the alloyed powders, thereby improving crystallinity and reducing crystal defects of the coatings [36]. 


\subsubsection{Hardness}

Figure 9 shows the hardness values of the WMoNbTaV HEA coatings as a function of milling time. Note that the coatings were heterogeneous and the hardness measurement was made in the place with the greatest thickness. The results reveal that the hardness increases with increasing milling time. The highest hardness value of $1308 \mathrm{HV} 0.025$ was obtained at $24 \mathrm{~h}$ of milling in the middle region of the coating, which is greater than that of $4 \mathrm{~h}$ of milling ( $988 \mathrm{HV}$ 0.025). It is believed that the uniform microstructure, high densification, and the formation of BCC sold solution phase obtained by a long milling duration $(24 \mathrm{~h})$ can significantly increase the hardness of the RHEA coating. On the other hand, Figure 10 exhibits the variation of hardness in the three model RHEA coatings milled for $24 \mathrm{~h}$. The WMoNbTaV HEA coating has the highest average hardness value of 1205 HV 0.025; however, the coating after annealing shows a relatively low hardness value ( $967 \mathrm{HV} 0.025$ on average). It should be pointed out that 304 stainless-steel substrates are intrinsically subject to embrittlement due to precipitation of second phases when exposed to high temperature for a long time [37]. However, annealing of the substrate is not a primary goal and beyond the scope of this study.

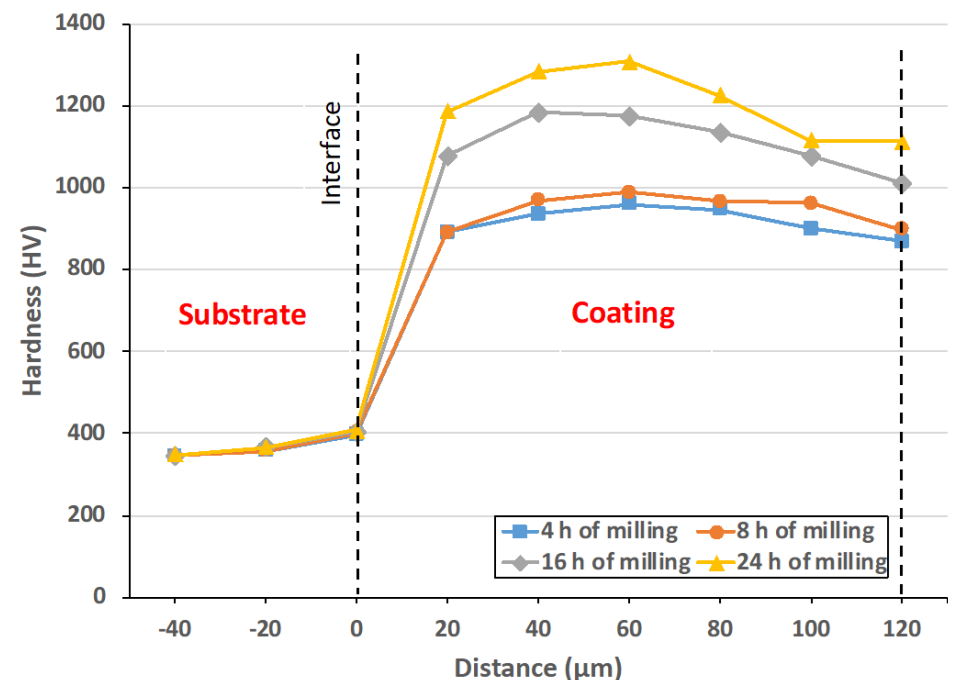

Figure 9. The microhardness distribution of the $\mathrm{WMoNbTaV} \mathrm{HEA} \mathrm{coating} \mathrm{at} \mathrm{different} \mathrm{milling} \mathrm{durations.}$

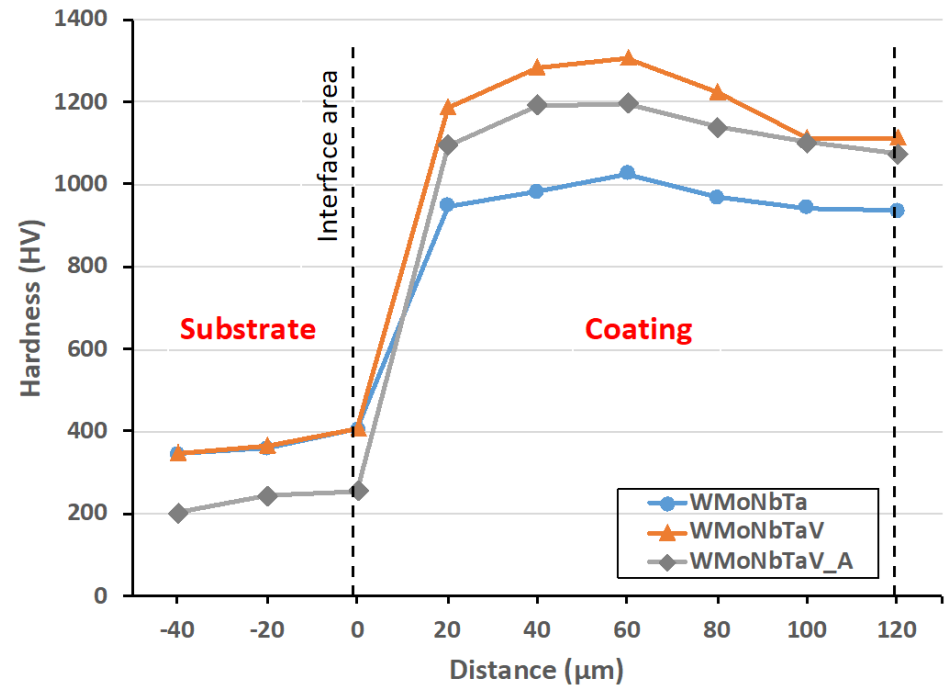

Figure 10. The microhardness distribution of the three model RHEA coatings milled for $24 \mathrm{~h}$ at various cross-sectional depths. 


\section{Conclusions}

The WMoNbTa and WMoNbTaV HEA coatings on the stainless-steel substrates were successfully fabricated by mechanical alloying. The XRD results show that a single solidsolution phase with BCC crystal structure forms in the WMoNbTa and WMoNbTaV HEA powders after $24 \mathrm{~h}$ of milling. The microstructure of the WMoNbTa HEA coating exhibits a non-uniform distribution of microstructure with a number of microcracks and pores. However, a homogeneous microstructure with a fine grain structure and high densification were observed in the WMoNbTaV HEA coating. It suggests that the presence of $\mathrm{V}$ elements plays an important role in determining microstructure evolution. It is reasonable to assume that the addition of $\mathrm{V}$ in the brittle RHEA coatings can provide the ductility of the alloy system and can therefore achieve a balance between cold welding and fracturing during ball milling, which encourages homogeneity of the materials. The WMoNbTaV HEA coating after annealing treatment indicates that a large number of oxides appeared as dark particles were found and have been identified as Ta-rich oxides. It implies that hightemperature annealing promotes a rapid reaction of the alloying elements and residual oxygen gas, resulting in the oxidation of materials. Additionally, the WMoNbTaV HEA coating has a much higher hardness (an increment of $\sim 25 \%$ ) than that of the RHEA coating after annealing. The results suggest that the annealing treatment can remove the effects of strain hardening generated by high-energy ball milling, which has a significant reduction in the hardness of the RHEA coating.

Author Contributions: Conceptualization, C.-L.C.; methodology, C.-L.C.; formal analysis, C.-L.C. and S.; investigation, S.; resources, C.-L.C.; writing-preparation, C.-L.C. and S.; writing-and editing, C.-L.C.; funding acquisition, C.-L.C. All authors have read and agreed to the published version of the manuscript.

Funding: This research was funded by Ministry of Science and Technology (MOST) Taiwan under the grant MOST 108-2221-E-259-017-MY2.

Institutional Review Board Statement: Not applicable.

Informed Consent Statement: Not applicable.

Data Availability Statement: No new data were created or analyzed in this study. Data sharing is not applicable to this article.

Conflicts of Interest: The authors declare no conflict of interest.

\section{References}

1. Yeh, J.W.; Chen, S.K.; Lin, S.J.; Gan, J.Y.; Chin, T.S.; Shun, T.T.; Tsau, C.H.; Chang, S.Y. Nanostructured high-entropy alloys with multiple principal elements: Novel alloy design concepts and outcomes. Adv. Eng. Mater. 2004, 6, 299-303. [CrossRef]

2. Miracle, D.B.; Senkov, O.N. A critical review of high entropy alloys and related concepts. Acta Mater. 2017, 122, $448-511$. [CrossRef]

3. Yeh, J.-W.; Yeh, J.W. Refractory high-entropy alloys (RHEAs) View project high-entropy alloys View project recent progress in high-entropy alloys. Ann. Chim. -Sci. Mater. 2006, 31, 633-648. [CrossRef]

4. Li, P.; Wang, A.; Liu, C.T. A ductile high entropy alloy with attractive magnetic properties. J. Alloys Compd. 2017, 694, 55-60. [CrossRef]

5. Zhao, Y.J.; Qiao, J.W.; Ma, S.G.; Gao, M.C.; Yang, H.J.; Chen, M.W.; Zhang, Y. A hexagonal close-packed high-entropy alloy: The effect of entropy. Mater. Des. 2016, 96, 10-15. [CrossRef]

6. Mohanty, S.; Maity, T.N.; Mukhopadhyay, S.; Sarkar, S.; Gurao, N.P.; Bhowmick, S.; Biswas, K. Powder metallurgical processing of equiatomic AlCoCrFeNi high entropy alloy: Microstructure and mechanical properties. Mater. Sci. Eng. A 2017, 679, 299-313. [CrossRef]

7. Tang, Z.; Yuan, T.; Tsai, C.W.; Yeh, J.W.; Lundin, C.D.; Liaw, P.K. Fatigue behavior of a wrought Al0.5CoCrCuFeNi two-phase high-entropy alloy. Acta Mater. 2015, 99, 247-258. [CrossRef]

8. Holcomb, G.R.; Tylczak, J.; Carney, C. Oxidation of CoCrFeMnNi High Entropy Alloys. JOM 2015, 67, 2326-2339. [CrossRef]

9. Xia, S.Q.; Yang, X.; Yang, T.F.; Liu, S.; Zhang, Y. Irradiation Resistance in Al xCoCrFeNi High Entropy Alloys. JOM 2015, 67, 2340-2344. [CrossRef]

10. Raman, L.; Guruvidyathri, K.; Kumari, G.; Murty, S.V.S.N. Phase evolution of refractory high-entropy alloy CrMoNbTiW during mechanical alloying and spark plasma sintering. J. Mater. Res. 2019, 34, 756-766. [CrossRef] 
11. Han, Z.D.; Chen, N.; Zhao, S.F.; Fan, L.W.; Yang, G.N.; Shao, Y.; Yao, K.F. Effect of Ti additions on mechanical properties of NbMoTaW and VNbMoTaW refractory high entropy alloys. Intermetallics 2017, 84, 153-157. [CrossRef]

12. Kareer, A.; Waite, J.C.; Li, B.; Couet, A.; Armstrong, D.E.J.; Wilkinson, A.J. Low activation, refractory, high entropy alloys for nuclear applications. J. Nucl. Mater. 2019, 526, 151744. [CrossRef]

13. Gorr, B.; Müller, F.; Azim, M.; Christ, H.J.; Müller, T.; Chen, H.; Kauffmann, A.; Heilmaier, M. High-Temperature Oxidation Behavior of Refractory High-Entropy Alloys: Effect of Alloy Composition. Oxid. Met. 2017, 88, 339-349. [CrossRef]

14. Senkov, O.N.; Semiatin, S.L. Microstructure and properties of a refractory high-entropy alloy after cold working. J. Alloys Compd. 2015, 649, 1110-1123. [CrossRef]

15. Wu, S.J.; di Wang, X.; Lu, J.T.; Qu, R.T.; Zhang, Z.F. Room-Temperature Mechanical Properties of V20Nb20Mo20Ta20W20 High-Entropy Alloy. Adv. Eng. Mater. 2018, 20, 1-8. [CrossRef]

16. Senkov, O.N.; Wilks, G.B.; Scott, J.M.; Miracle, D.B. Mechanical properties of Nb 25Mo $25 \mathrm{Ta} 25 \mathrm{~W} 25$ and V 20Nb $20 \mathrm{Mo} 20 \mathrm{Ta} 20 \mathrm{~W}$ 20 refractory high entropy alloys. Intermetallics 2011, 19, 698-706. [CrossRef]

17. Cheng, J.B.; Liang, X.B.; Xu, B.S. Effect of $\mathrm{Nb}$ addition on the structure and mechanical behaviors of CoCrCuFeNi high-entropy alloy coatings. Surf. Coat. Technol. 2014, 240, 184-190. [CrossRef]

18. Hsueh, H.T.; Shen, W.J.; Tsai, M.H.; Yeh, J.W. Effect of nitrogen content and substrate bias on mechanical and corrosion properties of high-entropy films (AlCrSiTiZr) 100-xN x. Surf. Coat. Technol. 2012, 206, 4106-4112. [CrossRef]

19. Sheng, W.; Yang, X.; Wang, C.; Zhang, Y. Nano-crystallization of high-entropy amorphous NbTiAlSiWx Ny films prepared by magnetron sputtering. Entropy 2016, 18, 226. [CrossRef]

20. Feng, X.; Zhang, J.; Xia, Z.; Fu, W.; Wu, K.; Liu, G.; Sun, J. Stable nanocrystalline NbMoTaW high entropy alloy thin films with excellent mechanical and electrical properties. Mater. Lett. 2018, 210, 84-87. [CrossRef]

21. Hung, S.-B.; Wang, C.-J.; Chen, Y.-Y.; Lee, J.-W.; Li, C.-L. Thermal and corrosion properties of V-Nb-Mo-Ta-W and V-Nb-Mo-Ta-WCr-B high entropy alloy coatings. Surf. Coat. Technol. 2019, 375, 802-809. [CrossRef]

22. Zhang, H.; Wu, W.; He, Y.; Li, M.; Guo, S. Formation of core-shell structure in high entropy alloy coating by laser cladding. Appl. Surf. Sci. 2016, 363, 543-547. [CrossRef]

23. Yue, T.M.; Xie, H.; Lin, X.; Yang, H.; Meng, G. Microstructure of laser re-melted AlCoCrCuFeNi high entropy alloy coatings produced by plasma spraying. Entropy 2013, 15, 2833-2845. [CrossRef]

24. Yao, C.Z.; Zhang, P.; Liu, M.; Li, G.R.; Ye, J.Q.; Liu, P.; Tong, Y.X. Electrochemical preparation and magnetic study of Bi-Fe-Co-NiMn high entropy alloy. Electrochim. Acta 2008, 53, 8359-8365. [CrossRef]

25. Deng, X.; Zhang, G.; Wang, T.; Ren, S.; Bai, Z.; Cao, Q. Investigations on microstructure and wear resistance of Fe-Mo alloy coating fabricated by plasma transferred arc cladding. Surf. Coat. Technol. 2018, 350, 480-487. [CrossRef]

26. Li, Y.; Chen, C.; Deng, R.; Feng, X.; Shen, Y. Microstructure evolution of Cr coatings on Cu substrates prepared by mechanical alloying method. Powder Technol. 2014, 268, 165-172. [CrossRef]

27. Ge, W.; Wu, B.; Wang, S.; Xu, S.; Shang, C.; Zhang, Z.; Wang, Y. Characterization and properties of CuZrAlTiNi high entropy alloy coating obtained by mechanical alloying and vacuum hot pressing sintering. Adv. Powder Technol. 2017, 28, 2556-2563. [CrossRef]

28. Shang, C.; Axinte, E.; Ge, W.; Zhang, Z.; Wang, Y. High-entropy alloy coatings with excellent mechanical, corrosion resistance and magnetic properties prepared by mechanical alloying and hot pressing sintering. Surf. Interfaces 2017, 9, 36-43. [CrossRef]

29. Kang, B.; Lee, J.; Ryu, H.J.; Hong, S.H. Ultra-high strength WNbMoTaV high-entropy alloys with fine grain structure fabricated by powder metallurgical process. Mater. Sci. Eng. A 2018, 712, 616-624. [CrossRef]

30. Suryanarayana, C.; Norton, M.G. X-Ray Diffraction: A Practical Approach; Plenum Press: New York, NY, USA, 1998.

31. Ji, W.; Wang, W.; Wang, H.; Zhang, J.; Wang, Y.; Zhang, F.; Fu, Z. Alloying behavior and novel properties of CoCrFeNiMn high-entropy alloy fabricated by mechanical alloying and spark plasma sintering. Intermetallics 2015, 56, 24-27. [CrossRef]

32. Pan, J.; Dai, T.; Lu, T.; Ni, X.; Dai, J.; Li, M. Microstructure and mechanical properties of Nb25Mo25Ta25W25 and Ti8Nb23Mo23Ta23W23 high entropy alloys prepared by mechanical alloying and spark plasma sintering. Mater. Sci. Eng. A 2018, 738, 362-366. [CrossRef]

33. Suryanarayan, C. Mechanical alloying and milling. Prog. Mater. Sci. 2001, 46, 1-184. [CrossRef]

34. Kilmametov, A.; Kulagin, R.; Mazilkin, A.; Seils, S.; Boll, T.; Heilmaier, M.; Hahn, H. High-pressure torsion driven mechanical alloying of CoCrFeMnNi high entropy alloy. Scr. Mater. 2019, 158, 29-33. [CrossRef]

35. Olier, P.; Couvrat, M.; Cayron, C.; Lochet, N.; Chaffron, L. Incidence of mechanical alloying contamination on oxides and carbides formation in ODS ferritic steels. J. Nucl. Mater. 2013, 442, S106-S111. [CrossRef]

36. Chen, C.-L. Microstructure and mechanical properties of AlCuNiFeCr high entropy alloy coatings by mechanical alloying. Surf. Coat. Technol. 2020, 386, 125443. [CrossRef]

37. Bahrami, A.; Taheri, P. A Study on the Failure of AISI 304 Stainless Steel Tubes in a Gas Heater Unit. Metals 2019, 9, 969. [CrossRef] 